\title{
Xanthoma striatum palmare
}

\author{
Alihan Oral and Nail Bambul
}

Department of Internal Medicine, Goztepe Training and Research Hospital, Istanbul Medeniyet University, Istanbul, Turkey
Received: August 16, 2015

Revised : October 5, 2015

Accepted: October 14, 2015

\section{Correspondence to}

Alihan Oral, M.D.

Tel: +90-554-614-2121

Fax: +90-216-570-9277

E-mail:dr.alihanoral@gmail.com
Fifty-year-old female without a known disease was admitted with weakness and fatigue. In family history, her sister had a myocardial infarction when she was 55 years old and hypertriglyceridemia, her father and mother have hypertension but don't have dyslipidemia. On physical examination body weight 76 $\mathrm{kg}$, height $165 \mathrm{~cm}$, body mass index 27.9 $\mathrm{kg} / \mathrm{m}^{2}$, abdominal circumference $92 \mathrm{~cm}$, xanthomas were found in her the palms (Fig. 1). Laboratory tests were as follows: serum cholesterol $480 \mathrm{mg} / \mathrm{dL}$ (normal range, o to 150), triglycerides $627 \mathrm{mg} / \mathrm{dL}$ (normal range, o to 150), high density lipoprotein $44 \mathrm{mg} / \mathrm{dL}$ (normal range, 35 to 65), low density lipoprotein 102 (normal range, <130), fasting glucose $95 \mathrm{mg} /$ $\mathrm{dL}$ (normal range, 82 to 115), hemoglobin Alc 6\%, hemoglobin $10 \mathrm{~g} / \mathrm{dL}$ (normal range, 13 to 18), mean corpuscular volume $102 \mathrm{fL}$ (normal range, 80 to 97 ), leukocyte $10,000 / \mathrm{mm}^{3}$ (normal range, 4 to 10,000 ), platelet $102,000 / \mathrm{mm}^{3}$ (normal range, 142 to 424,000 ), vitamin $\mathrm{B} 12$ $46 \mathrm{pg} / \mathrm{mL}$ (normal range, 187 to 880 ), and folate $8.1 \mathrm{ng} / \mathrm{mL}$ (normal range, 3 to 20). But due to technical insufficiencies of our hospital's biochemical laboratory; lipoprotein electrophoresis, apolipoprotein E typing, phospholipid testings could not be revealed. Peripheral blood smear confirmed megaloblastic anemia. We thought it could possibly familial type III hyperlipoproteinemia $\left(\mathrm{T}_{3} \mathrm{HL}\right)$ and megaloblastic anemia. She was started on fibrate and cobalamin treatments. After 3 months of follow-up triglycerides and total cholesterol was back to normal. The presence of xanthomas continued.

$\mathrm{T}_{3} \mathrm{HL}$, which is characterized by the accumulation of $\beta$ very low density lipoprotein, may be considered as an early atherosclerosis indicator. Palmar xanthoma (palmar xanthoma striatum) is a rare but is an early and specific marker of $\mathrm{T}_{3} \mathrm{HL}$.

\section{Conflict of interest}

No potential conflict of interest relevant to this article was reported.

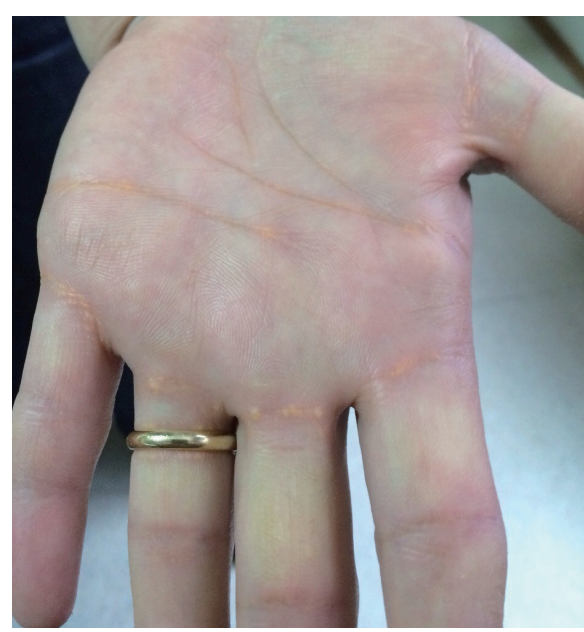

Figure 1. Xanthomas are seen in the palm. 